\title{
Significance of microhaematuria in young adults
}

\author{
P FROOM，J RIBAK，J BENBASSAT
}

\begin{abstract}
The medical records of 1000 asymptomatic male air force personnel were examined retrospectively for the results of 15 yearly examinations of urinary sediment. The study covered the period 1968-82, beginning with the subjects aged 18-33 years. The cumulative incidence of two to four or more red blood cells per high power field found at one or more examinations was $38.7 \%$ after an average of 12.2 yearly examinations per person. In 161 subjects two to four or more red blood cells per high power field were found at two or more yearly examinations within a five year period.

Intravenous pyelography in $\mathbf{5 8}$ cases disclosed asymptomatic nephrolithiasis in six. Cystoscopy performed in 11 cases identified one patient with urethritis, one with a vesical calculus, and one with transitional cell carcinoma of the bladder. Two years before diagnosis the patient with carcinoma had had a single transient finding of 10-12 red blood cells per high power field which was not investigated further. Cystoscopy was performed after an episode of macroscopic haematuria. Renal biopsy in one subject with recurrent microhaematuria and trace proteinuria disclosed focal glomerulonephritis. None of the remaining subjects with microhaematuria developed hypertension or proteinuria, and at the end of the study period all were active and free of urinary symptoms.

The observed cumulative incidence of urological neoplasms at 15 years $(0 \cdot 1 \%)$ was consistent with that expected in Israeli men aged 18-40 (0.09\%). Hence microhaematuria detected during a screening examination probably should not be regarded as a specific sign of a significant lesion and does not of itself warrant urological investigation in adults aged 40 or less.
\end{abstract}

\section{Introduction}

There is general agreement that asymptomatic isolated microhaematuria in adults warrants urological investigation including intravenous pyelography and cystoscopy. ${ }^{1-9}$ Serious urological lesions have been reported in $5 \%,{ }^{1} 20 \%,{ }^{2} 14 \cdot 2 \%,{ }^{3}$ and $11 \%{ }^{4}$ of patients referred for microhaematuria. It has therefore been recommended that "any red blood cell seen in a centrifuged specimen of urine be considered significant" and that a complete investigation into its cause is mandatory. ${ }^{5}$ Urological investigation, however, fails to disclose the cause of isolated microhaematuria in many if not most cases, 2410 and for these patients kidney biopsy11-13 and biannual intravenous pyelography and cystoscopy have been recommended. ${ }^{3}$ Others argue that kidney biopsy seldom leads to alterations in management of isolated microhaematuria and suggest follow up without biopsy. ${ }^{71} 15$

Israel Air Force Aeromedical Center, Tel Hashomer, Israel P FROOM, MD, consulting physician and flight surgeon J RIBAK, MD, director of IAF Aeromedical Center

Department of Medicine, Hadassah University Hospital at Mount Scopus, Jerusalem, Israel

J BENBASSAT, MD, professor of medicine

Correspondence to: Dr P Froom, Maagan Michael DN, Menashe, Israel 37805.
The number of red blood cells excreted is thought not to be related to the severity of the lesion. ${ }^{1-3} 5$ Hence we have no criteria with which to identify patients with microhaematuria in whom the probability of a significant lesion is low enough to justify exemption from investigation. ${ }^{1}$

Few reports examine the incidence of urological lesions in young adults with microhaematuria. Greene et $a l^{1}$ found that the incidence of urological abnormalities in patients with microhaematuria increased from $27.3 \%$ in those aged 30 or less to $83 \%$ in those aged 70 or more. They found no urological neoplasms among subjects with microhaematuria younger than $50 .{ }^{1}$ Carson et al reported that 38 out of 40 significant urological lesions associated with microhaematuria occurred in patients aged 50 or more. ${ }^{2}$ On the other hand, out of 22 patients aged 1841 with isolated microscopical haematuria, four had lesions requiring surgical correction, including one case of asymptomatic papillary carcinoma of the bladder. The author concluded that "hematuria in a young man warrants a prompt, complete, urologic investigation."

Opposite conclusions were reached in separate surveys of $8954^{18}$ and $6070^{17}$ schoolchildren. The prevalence of isolated microhaematuria was $4 \cdot 1 \%$ in one or more of four examinations ${ }^{16}$ and $0.5 \%$ in two of three examinations. ${ }^{17}$ Comparison of these figures with the yearly mortality of renal disease suggested that almost all of these children had either no renal disease or a self limiting condition. The authors concluded that in children "the presence of red cells is usually not significant, early inclusion of $x$ ray and urologic investigation is not warranted,"16 and "renal biopsy is not indicated for microhaematuria alone."1?

These differences in recommendations for management of microhaematuria may be due to differences either in age or in nature of the populations studied. All studies reporting a high incidence of urological lesions in patients with microhaematuria were performed in referred adults. Those failing to show a high incidence of lesions were carried out on unselected populations of children. Microhaematuria in adults is more likely to be associated with serious disease, because significant urological lesions are rare in children ${ }^{16} 1$ ? and their incidence increases with age ${ }^{18}$ (Central Bureau of Statistics, Ministry of Health, Israel). Information derived from observations on referred patients may have been distorted by selection bias.

The degree of diagnostic work up indicated for isolated microhaematuria detected in asymptomatic young adults during a screening examination is uncertain. The question is whether we should subject them to intravenous pyelography and cystoscopy or risk missing a significant lesion. To answer this question we have compared the cumulative incidence of microhaematuria and of significant urological lesions in 1000 young adults examined yearly for 15 years.

\section{Subjects and methods}

The medical files of a sample of men aged 18-33 in 1968 were selected using a random number sequence from the records of the Israel Air Force. The files of subjects who had died during the survey period 1968-82 and those of 54 subjects who had had fewer than five consecutive yearly examinations were excluded. None of the subjects had died of urological or kidney disease. The remaining 1000 files were reviewed and the following data compiled: results of urine analysis; blood pressure; sedimentation rate; and, if available, results of intravenous pyelography and cystoscopy, serum urea and creatinine concentrations, and creatinine clearance.

Yearly examinations in the studied population averaged 12.2 per person. All but 48 of the 1000 subjects were followed up throughout the 
15 years and seen during the last two years. The 15 year period was subdivided into three five year periods. All subjects had completed all yearly examinations in at least one five year period, 859 had had all yearly examinations for at least two five year periods, and 411 had had all 15 examinations. The degree of work up in cases found to have microhaematuria had been at the discretion of individual physicians.

Urine analysis was carried out between 1968 and 1982 by five experienced technicians. Within three hours after voiding, $10 \mathrm{ml}$ of the second morning urine sample was spun in tapered test tubes at $1950 \mathrm{rpm}$. The supernatant was poured off and the remainder (roughly $0.3 \mathrm{ml}$ ) mixed, placed on a slide, covered with a standard glass slip, and examined with a $\times 40$ plane objective and $\times 10$ wide field binoculars. Ten to 20 high power fields were examined and the results expressed as a range of the most common values, as follows: $1-3,2-4,3-5,5-8$, and $>8$ red blood cells per high power field.

\section{Results}

The point prevalence of a finding of two to four or more red blood cells per high power field in 12227 urine analyses in the 1000 men was $5.2 \%$ and that of over eight red blood cells $1 \%$. The cumulative incidence of two to four or more red blood cells per high power field during the 15 years was $38.7 \%$ (table I). In 161 subjects two to four or more red blood cells per high power field recurred on two or more yearly examinations within at last one five year period. Mean follow up after the onset of microhaematuria was 7.6 years, with 140 of the 161 subjects with recurrent microhaematuria being followed up for at least five years.

Intravenous pyelography was performed in 58 subjects. A review of their records showed that all of them had asymptomatic microhaematuria of two to four or more red blood cells per high power field on at least two out of five consecutive yearly examinations. In general the higher the grade of microhaematuria the more likely was intravenous pyelography to be performed (table II). Urolithiasis was found in six of these 58 cases. Two patients with urolithiasis were operated on even though neither had signs of obstruction or recurrent infections. Two remained asymptomatic, and the other two developed renal colic four and seven years later.

Cystoscopy was performed in 11 cases. One patient who had a single transient finding of 10 to 12 red blood cells per high power field was found to have a vesical calculus. Another had urethritis. A third patient had transitional cell carcinoma of the bladder. Two years before diagnosis this patient had had a single transient finding of 10 to 12 red blood cells per high power field. Two months before diagnosis he complained of macroscopic haematuria. Repeated examinations within two months after that episode showed one to three red cells per high power field on one occasion and no red cells on four occasions. Cystoscopy was performed after a further episode of macroscopic haematuria. Two years after diagnosis and surgery he was free of disease and had no symptoms.

TABLE I-Cumulative incidence of microhaematuria in 1000 men followed up for 15 years, by grade of microhaematuria and number of positive test results within five consecutive yearly examinations

No of positive test results Red blood cells per high power field (equal or more)

\begin{tabular}{lcccc} 
No of positive test results & \multicolumn{4}{c}{ Red blood cells per high power field (equal or more) } \\
\cline { 2 - 5 } yearly examinations & $2-4$ & $3-5$ & $5-8$ & Over 8 \\
\hline One or more & 387 & 257 & 148 & 78 \\
Two or more & 161 & 107 & 59 & 15 \\
Three or more & 79 & 56 & 24 & 9
\end{tabular}

TABLE II-Incidence of asymptomatic urolithiasis in subjects with recurrent jicrohaematuria in whom intravenous pyelography was performed, by grade of microhaematuria and number of positive test results within five consecutive yearly examinations

\begin{tabular}{|c|c|c|c|c|c|}
\hline \multirow{2}{*}{\multicolumn{2}{|c|}{ No of positive test results }} & \multicolumn{4}{|c|}{$\begin{array}{l}\text { Red blood cells per high } \\
\text { power field (equal or more) }\end{array}$} \\
\hline & & \multirow{2}{*}{$\begin{array}{r}2-4 \\
161 \\
58 \\
6\end{array}$} & \multirow{2}{*}{$\begin{array}{r}3-5 \\
107 \\
51 \\
5\end{array}$} & \multirow{2}{*}{$\begin{array}{r}5-8 \\
59 \\
34 \\
5\end{array}$} & \multirow{2}{*}{$\begin{array}{r}\text { Over } 8 \\
15 \\
14 \\
2\end{array}$} \\
\hline Two or more & $\begin{array}{l}\text { Total cases } \\
\text { Intravenous pyelography performed } \\
\text { Urolithiasis }\end{array}$ & & & & \\
\hline Three or mor & $\begin{array}{l}\text { Total cases } \\
\text { Intravenous pyelography performed } \\
\text { Urolithiasis }\end{array}$ & $\begin{array}{r}79 \\
45 \\
4\end{array}$ & $\begin{array}{r}56 \\
30 \\
4\end{array}$ & $\begin{array}{r}24 \\
14 \\
3\end{array}$ & $\begin{array}{l}9 \\
9 \\
1\end{array}$ \\
\hline
\end{tabular}

Renal biopsy performed in one subject with two to four red blood cells per-high power field and traces of proteinuria at four out of five examinations showed focal glomerulonephritis. Except for this man, none of the subjects with haematuria developed proteinuria. There were no differences in erythrocyte sedimentation rates between subjects with and without microhaematuria. Hypertension occurred in seven subjects without microhaematuria but in none of those with microhaematuria. Serum urea and creatinine concentrations and creatinine clearance were determined in 16 of the subjects with recurrent microhaematuria and found to be normal. All other subjects with microhaematuria remained asymptomatic and without other evidence of urological disease.

\section{Discussion}

The main finding of our longitudinal study was a high cumulative incidence of microhaematuria on one or more yearly examinations. Intravenous pyelography, cystoscopy, and kidney biopsy were not performed in most of the subjects with microhaematuria. Nevertheless, we believe that urological malignancies and serious progressive renal disorders were not missed, for two reasons: firstly, our subjects were followed up for an average of 7.6 years after detection of microhaematuria; and, secondly, the observed cumulative incidence of urological neoplasms (one case per 1000) was consistent with the expected 15 year incidence $(0.09 \%)$ among the same age group in Israel (Central Bureau of Statistics, Ministry of Health) and the United States. ${ }^{18}$

Asymptomatic subjects excrete red cells in the urine. Authors employing direct red cell counts by haemacytometer have reported that daily excretions of red cells in healthy people vary from 30000 up to $2000000 .^{1619-21}$ Similar to our results, authors using the high power field method in studies of unselected adults have reported "normal" values (95\% of tested specimens) of less than three red blood cells per high power field. ${ }^{21-24}$ Freni et al, however, concluded after a careful screening of 432 men aged 50 or more that the line between physiological and pathological haematuria should be drawn, if at all, at eight red cells per high power field. ${ }^{25}$ Correlations between the results of microscopical examinations of the urinary sediment (the high power field method) and direct counts of red cells by haemacytometer are reportedly poor. ${ }^{20}: 60$ The main causes for the relatively low sensitivity and accuracy of the high power field method are differences in the volume of the centrifuged specimen, volume of discarded supernatant, thoroughness of mixing the specimen before and after centrifugation and the width of the sediment layered on the slide. ${ }^{26} 27$

Our findings should be interpreted with caution. They are drawn from a rigorously selected sample of young adults who may not be representative of the general population. Nevertheless, until the results of studies of unselected populations become available some tentative conclusions are justified. We think that the low specificity of isolated microhaematuria, the inaccuracy of the high power field method, and the uncertainty about the precise definition of pathological microhaematuria preclude its efficacy as a screening test for urological malignancies and progressive, treatable renal disease in adults aged $\mathbf{4 0}$ or less. Our findings argue against inclusion of renal biopsy and cystoscopy in asymptomatic young adults with isolated microhaematuria. The recommendations in most textbooks 8 of urological investigation for all cases of microhaematuria of any degree probably derive from observations in referred individuals aged 40 or more, in whom the prevalence of urological malignancies is relatively high ${ }^{18}$ (Central Bureau of Statistics Ministry of Health, Israel). Implementing these recommendations in adults aged 40 or less would have necessitated the inconvenience, expense, anxiety, and morbidity of renal biopsy and cystoscopy in up to 385 of our subjects in order to detect, at best, neoplasms in $0.1 \%$ and benign, non-progressive renal disease in an uncertain number of others.

Although detection of urothelial malignancies and progressive renal disease was extremely rare, silent stones were found in $10.3 \%$ of the subjects with recurrent microhaematuria in 
whom intravenous pyelography was performed (table II). The prevalence of silent urolithiasis in the general population is unknown. It is therefore uncertain if and to what degree the finding of recurrent microhaematuria in an asymptomatic young adult increases the probability of urolithiasis. Furthermore, the course of silent urolithiasis has not been studied. It is therefore uncertain whether the benefit of its early detection and management exceeds the morbidity, inconvenience, and cost of intravenous pyelography in 10 young adults in order to detect urolithiasis in one. We believe that until data on the prevalence and natural history of silent urolithiasis become available, persons aged 40 or less with asymptomatic microhaematuria should be followed up without invasive investigations. Furthermore, we would not recommend screening for haematuria in asymptomatic young men, since positive results do not justify further work up or treatment.

\section{References}

1 Greene LF, O'Shaughnessy EJ, Hendricks ED. Study of five hundred patients with asymptomatic microhematuria. $7 A M A$ 1956;161:610-3.

${ }^{2}$ Carson CC, Segura JW, Greene LF. Clinical importance of microhematuria. $f A M A$ 1979;241:149-50.

3 Golin AL, Howard RS. Asymptomatic microscopic hematuria. $f$ Urol 1980;124:389-91.

4 Burkholder GV, Dotin LN, Thomason WB, Beach PD. Unexplained hematuria. FAMA 1969;210:1729-33.

5 Harrison JH, Gittes RF, Perlmutter AD, Stamey TA, Walsh PC, eds. Campbell's urology. 4th ed. Philadelphia: W D Saunders Co, 1976.

- Wallace DM, Harris DL. Delay in treating bladder tumours. Lancet 1965 ;ii :332-4.

'Benson GS, Brewer ED. Hematuria: algorithms for diagnosis. $\mathcal{f} A M A$ $1981 ; 246$ : $993-5$.

8 Brenner BM, Rector FC, eds. The kidney. 2nd ed. Philadelphia: W D Saunders Co, 1981.
9 Gartman E. The significance of hematuria in young men. $f$ Urol 1956;75: 135-42.

${ }^{10}$ Anonymous. Undiagnosed haematuria [Editorial]. Br Med f 1975 ;i :647.

11 Ferris TF, Gordon P, Kashgarian M, Epstein FH. Recurrent hematuria and focal nephritis. $N$ Engl $f$ Med 1967;276:770-5.

12 Michael J, Jones NF, Davies DR, Tighe JR. Recurrent haematuria: role of renal biopsy and investigative morbidity. $\mathrm{Br} \mathrm{Med} \mathcal{F}$ 1976; : 686-8.

${ }^{13}$ Chen BTM, Ooi BS, Tan KK, Khoo OT. Causes of recurrent hethaturia. $Q \mathcal{F}$ Med 1972;41:141-8.

14 Paone DB, Meyer LE. The effect of biopsy on therapy in renal disease. Arch Intern Med $1981 ; 141: 1039-41$.

${ }^{15}$ Pardo V, Berian MG, Levi DF, Strauss J. Benign primary hematuria, Clinicopathologic study of 65 patients. Am F Med 1979;67:817-22.

16 Vehaskari VM, Rapola J, Koskimies O, Savilahti E, Vilska J, Hallman N. Microscopic hematuria in school children: epidemiology and clinicopathologic evaluation. $\mathcal{F}$ Pediatr 1979 ;95:676-84.

17 Dodge WF, West EF, Smith EH. Proteinuria and hematuria in schoolchildren: epidemiology and early natural history. $\mathcal{F}$ Pediatr 1976;88: $327-47$.

18 Silverberg E. Urologic cancer, statistical and epidemiologic information. New York: American Cancer Society, 1973.

19 Rofe P. The cells of notmal human urine. 7 Clin Pathol 1955;8:25.

${ }^{20}$ Kesson AM, Talbott JM, Gyory AZ. Microscopic examination of urine. Lancet 1978 ;ii :809-12.

${ }^{21}$ Sanders C. Clinical urine examination and incidence of microscopic haematuria in apparently normal males. Practitioner 1963;191:192-7.

22 Wright WT. Cell counts in urine. Arch Intern Med 1959;103:76-8.

${ }^{23}$ Larcom RC, Carter GH. Erythrocytes in urinary sediment: identification and normal limits. F Lab Clin Med 1948;33:875-80.

24 Free HM, Free AH, Giordana AS. Studies with a simple test for detection of occult blood in urine. $\mathcal{F}$ Urol 1956;75:743-52.

${ }^{25}$ Freni SC, Henderik GJ, Hol C. Centrifugation techniques and reagent strips in the assessment of microhaematuria. $\mathcal{F}$ Clin Pathol 1977;30: $336-40$.

${ }^{26}$ Bee DE, James GP, Paul KL. Hemoglobinuria and hematuria: accuracy and precision of laboratory diagnosis. Clin Chem 1979;25:1696-9.

27 Gadeholt $\mathbf{H}$. Quantitative estimation of urinary sediment with special regard to sources of error. $\mathrm{Br} \mathrm{Med} \mathcal{F} 1964 ; \mathrm{i}: 1547-50$.

(Accepted 13 October 1983)

\title{
Electroconvulsive therapy: results in depressive illness from the Leicestershire trial
}

\author{
S BRANDON, P COWLEY, C MCDONALD, P NEVILLE, R PALMER, S WELLSTOOD-EASON
}

\begin{abstract}
Electroconvulsive therapy was investigated in a double blind trial. Altogether 186 clinically selected patients were referred to the trial, but 48 of these did not participate. According to the present state examination, 95 of the remaining 138 patients fell into one of the classes of major depression. Patients were randomly allocated to a course of real or simulated electroconvulsive therapy. Treatment was given twice a week with a maximum of eight treatments. On the Hamilton depressive rating scale the improvement in the group given real treatment was significantly greater than that in the group given simulated treatment both at two weeks $(p=0.014)$ and at
\end{abstract}

\footnotetext{
Department of Psychiatry, University of Leicester, Leicester Royal Infirmary, PO Box 65, Leicester LE2 7LX

$S$ BRANDON, MD, FRCPSYCH, professor

P COWLEY, BMEDSCI, MRCPSYCH, lecturer

C MCDONALD, MA, research assistant

P NEVILLE, BM, MRCPSYCH, senior registrar

R PALMER, MB, MRCPSYCH, senior lecturer

$S$ WELLSTOOD-EASON, MRCS, LRCP, MRCPSYCH, lecturer

Correspondence to: Professor $S$ Brandon.
}

four weeks ( $p=0.0001)$. At follow up at 12 and 28 weeks there was no difference between the treatment groups. At the end of the four week trial consultants, who were blind to the allocation of treatment, rated the patients who had received real treatment as having made a significantly greater improvement than the patients who had received simulated treatment $(p<0.00005)$. Further analysis showed that electroconvulsive therapy was effective in depression associated with delusions and in depression associated with retardation.

\section{Introduction}

Although the Royal College of Psychiatrists was able in 1977 to say that the evidence in favour of electroconvulsive therapy in depressive states seemed incontrovertible, ${ }^{1}$ serious doubts continued to be expressed, not least by lay pressure groups, who in some : parts of the world achieved the abolition or serious restriction of this treatment. Lambourn and Gill in a double blind controlled trial compared unilateral brief pulse electroconvulsive therapy with simulated treatment and found no significant difference in outcome. ${ }^{2}$ Freeman et al undertook a study in which a control group received two "dummy" applications of electroconvulsive therapy before proceeding to a 